\title{
ROBINSON, Ian S., Die Chroniken Bertholds von Reichenau und Bernolds von Konstanz, 1054-1100
}

\section{Philippe Depreux}

\section{OpenEdition}

\section{Journals}

Édition électronique

URL : http://journals.openedition.org/ifha/943

DOI : $10.4000 /$ ifha. 943

ISSN : 2198-8943

Éditeur

IFRA - Institut franco-allemand (sciences historiques et sociales)

Référence électronique

Philippe Depreux, «ROBINSON, Ian S., Die Chroniken Bertholds von Reichenau und Bernolds von Konstanz, 1054-1100», Revue de l'IFHA [En ligne], Date de recension, mis en ligne le 01 janvier 2004, consulté le 22 septembre 2020. URL : http://journals.openedition.org/ifha/943 ; DOI : https://doi.org/10.4000/ ifha. 943

Ce document a été généré automatiquement le 22 septembre 2020.

(C)IFHA 


\title{
ROBINSON, Ian S., Die Chroniken Bertholds von Reichenau und Bernolds von Konstanz, 1054-1100
}

\author{
Philippe Depreux
}

1 Les chroniques de Berthold, moine de la Reichenau, et de Bernold, prêtre du diocèse de Constance, dont il fréquenta l'école cathédrale, et qui s'illustra par la rédaction de nombreux traités polémiques, comptent parmi les témoignages les plus précieux dont l'historien de la Réforme grégorienne dispose sur les controverses qu'elle souleva et les tensions politiques qu'elle suscita (les auteurs se montrant tous deux hostiles à l'empereur Henri IV). Conçue comme une continuation de la chronique d'Hermann le Perclus († 1054), le maître de Berthold, la chronique du moine de la Reichenau est transmise sous deux versions, dont la première n'est connue que par une édition du début du XVIe s. et s'achève à l'année 1066, alors que la seconde, transmise par 5 manuscrits, se poursuit jusqu'en 1080. Suite à l'édition de cette chronique par G. H. Pertz en 1844, l'identification de l'auteur et les phases de rédaction des textes firent l'objet d'analyses contradictoires, auxquelles la présente édition apporte un terme en proposant un texte bien établi ; les deux versions sont éditées en vis-à-vis, de manière à en faciliter la comparaison. L'établissement des emprunts s'avérait également nécessaire en ce qui concerne la chronique de Bernold, qui couvre les années 1054-1100, et présente des similitudes avec celle de Berthold. Outre le manuscrit autographe, conservé à Munich ( $\mathrm{Clm}$ 432), le texte de cette chronique, concernant laquelle il ne se posait pas de question particulière quant à l'identification de l'auteur, est transmis par 7 manuscrits. Une copieuse introduction (près de 160 p.) présente en détail la tradition manuscrite et diverses analyses stylistiques ; une centaine de pages d'index viennent clore cette édition du texte latin, que l'éditeur a publié ailleurs avec une traduction allemande (dont on ne trouve pas mention dans ce volume) : I.S.R. (éd.), Bertholds und Bernolds Chroniken, traduction par Helga Robinson-Hammerstein et I.S.R., Darmstadt : Wissenschaftliche Buchgesellschaft (Ausgewählte Quellen zur deutschen Geschichte des Mittelalters. Freiherr vom Stein-Gedächnisausgabe, 14), 2002. Ces deux publications sont complémentaires ; si la traduction peut s'avérer utile quant 
à l'interprétation du texte, l'édition des MGH constitue la version de référence, tant du point de vue de l'analyse philologique que de l'érudition historiographique.

2 Philippe DEPREUX (MHFA) 